\title{
Farewell from the Hernia Editorial Team
}

\author{
M. Miserez ${ }^{1}$ R. J. Fitzgibbons $\mathrm{Jr}^{2} \cdot$ A. Montgomery ${ }^{3} \cdot$ Y. Novitsky $^{4}$
}

Received: 18 August 2018 / Accepted: 19 August 2018 / Published online: 10 October 2018

c) Springer-Verlag France SAS, part of Springer Nature 2018

Dear Hernia reader,
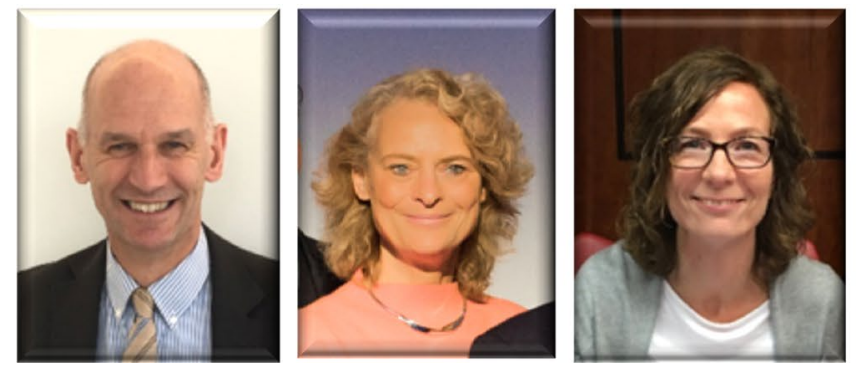

Editors and Editorial Assistants of Journal Hernia-from left: Editorin-Chief EHS Marc Miserez, Associate Editor EHS Agneta Montgomery, Editorial Assistant EHS Susanne Heeren, Editorial Assistant

In this editorial, we want to update you on the status of the Hernia Journal, which is, for the time being, still the official journal of the EHS, AHS and APHS. During the International Hernia Congress organized in Miami jointly by the AHS and EHS last March, we discussed the many ongoing and planned initiatives to maintain and improve the status of the journal. In the past there has been an issue with the long review times, but we are happy to say that due to a strong investment of the editorial office and all reviewers, the time from submission to first decision has decreased with $38 \%$ from 65 days in 2012 to 40 days in the first half of 2018 . We could give you numerous examples of other efforts, and we are pleased to inform you that all your commitments to support the journal as member, author, or reviewer have been very successful. The 2017 IF of Hernia has risen to 2.417;

\footnotetext{
M. Miserez

marc.miserez@uzleuven.be

UZ Leuven, Herestraat 49, 3000 Leuven, Belgium

Omaha, USA

Malmö, Sweden

New York, USA
}
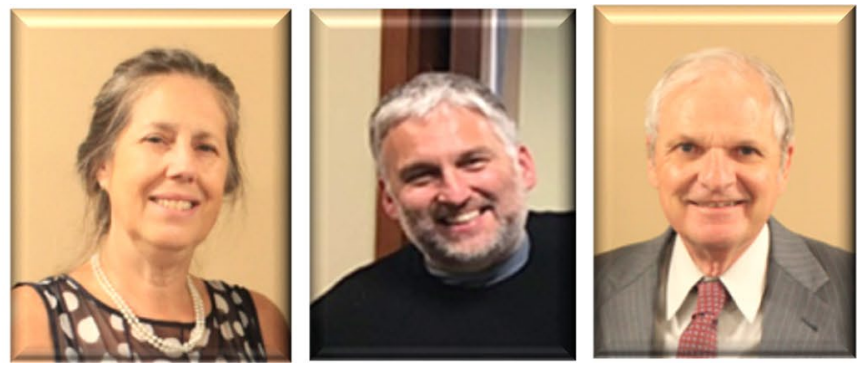

AHS Rhonda Peavy, Associate Editor AHS Yuri Novitsky and Editorin-Chief AHS Robert Fitzgibbons

this is a $25 \%$ increase compared to the IF of 2016 . With the publication of certain high-quality manuscripts in the last 2 years which are being cited often such as the International guidelines for groin hernia management (Hernia 2018; 22: $1-165)$, we are anticipating an even greater improvement in 2019 and 2020 as the impact factor is based on citations over the preceding 2 years.

Springer as publisher and owner of the Hernia journal informed the leadership of EHS and AHS shortly after the meeting in Miami of plans to take over full editorial control as of Jan 1, 2019 without a preceding discussion. This means the publishing agreement with the societies will not be renewed and the collaboration with the current editors and editorial assistants will cease. The reason for this is completely unclear, but the decision was non-negotiable. You can certainly understand that we as the Hernia editorial team are extremely humiliated and disappointed with this decision and the way we were informed. Many months later, we were told that Prof G. Campanelli, current pastpresident of EHS, will become the new Editor-in-Chief. It is still completely unclear what the new structure will look like and how the publisher plans to organize the transition.

A new affiliation agreement with the EHS, AHS and APHS is currently under negotiation. In this way there will 
still be a platform for publishing research work and the annual congress abstract book in Hernia.

The Journal Hernia would not have enjoyed its success and renown without the valuable contribution of its authors, reviewers, Section Editors and whole editorial staff. We strongly believe we were heading in the right direction and we thank all persons who have contributed to the success of the Journal. We would like to mention in particular our editorial assistants Susanne Heeren and Rhonda Peavy, who have been treating Hernia as their baby during so many decades and for whom this decision came also as a blow. We are extremely indebted to them.
We wish you all the best.

Kind regards,

Bob Fitzgibbons and Marc Miserez, Editors-in-Chief

Agneta Montgomery and Yuri Novitsky, Associate Editors

\section{Compliance with ethical standards}

Conflict of interest The author(s) declare that they have no competing interests other than their working relationship with Springer. 